\title{
Development of a novel design approach for rigid landslide debris-resisting barriers
}

\author{
Anthony L Wong* \\ Geotechnical Engineering Office, Civil Engineering and Development Department, the HKSAR Government, Hong Kong, \\ People's Republic of China
}

\begin{abstract}
Natural terrain landslides pose a global threat as they often cause casualties and economic losses. Potential impacts of climate change could further aggravate the landslide risk and robust mitigation measures such as rigid debris-resisting barriers are particularly important in protecting lives and properties. Traditionally, rigid barriers are designed based on empirical approaches which generally oversimplify the dynamic nature of debris-barrier interaction. This often results in overlyconservative designs where the barrier structures are not only bulky and environmentally intrusive, but also difficult to construct. There is thus a pressing need to optimise the design approach. In this regard, the Geotechnical Engineering Office has been endeavouring to enhance the process efficiency, in collaboration with top-notch experts, by capitalising on the latest advancement in computational simulations and physical testing, and improving the understanding of the physical process. A technical breakthrough has been achieved with respect to an improved knowledge in the debris flow dynamic and the complex debris-barrier interaction. A novel design method covering geotechnical and structural aspects has been developed for use in Hong Kong. This would bring about more cost-effective barrier designs, with enhanced design reliability and robustness.
\end{abstract}

KEYWORDS Debris Flow; rigid debris-resisting barrier; physical modelling; analytical modelling; numerical analyses; climate change CONTACT Anthony L Wong anthonywong@cedd.gov.hk

Received 7 March 2021

\section{Introduction}

Natural terrain landslides are among the most dangerous natural processes worldwide, threatening lives and properties. While landslides can be rain-induced, the effect of climate change could further aggravate the risk of devastating landslides. Extensive scientific research on probable climatic changes (e.g. EB, 2015) indicates that extreme rainfall events will become more frequent and intense. For example, in Hong Kong, the hourly rainfall record at the Hong Kong Observatory was broken several times in the past few decades, whereas it used to take several decades to break such record in the past. The record-breaking rainstorm in 2008 triggered some 2,400 landslides in Lantau (an outlying island in Hong Kong with a land area of less than $150 \mathrm{~km}^{2}$; see Figure 1).

(a)

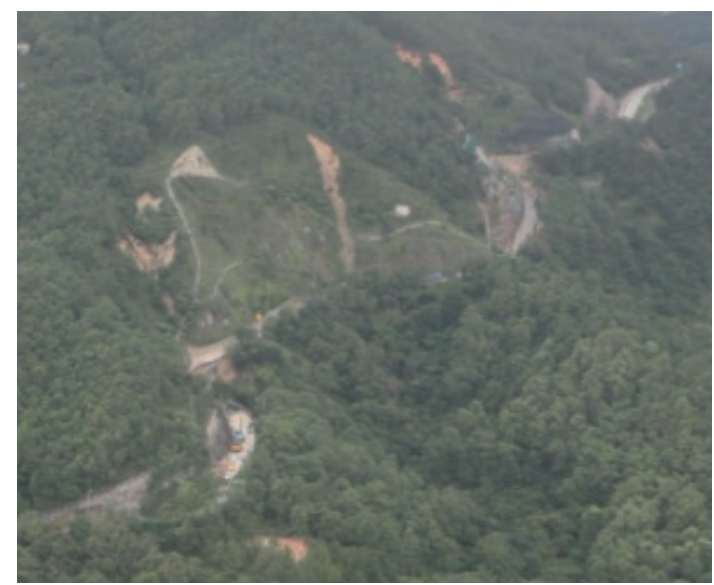

(b)

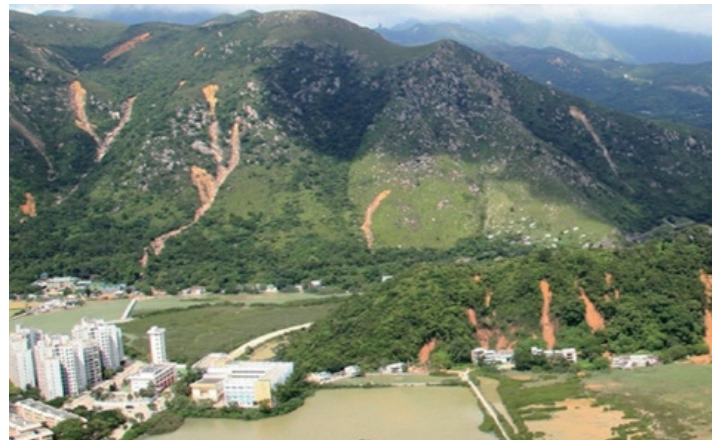

Figure 1. Photographs of natural terrain landslides in Hong Kong in 2008.

Reinforced concrete rigid barriers have been widely used to mitigate large debris flow events, so as to ensure public safety. Traditional design methods (e.g. CAGHP, 2018; Hungr, 1984; Kwan, 2012) comprise some empirical design procedures containing oversimplified design parameters, which overlook the dynamic nature of boulder impact and barrier response (Figure 2). Based on local experience, barriers so designed are not only bulky in size and environmentally intrusive, but also contain extensive tie-back foundations and congested steel reinforcements. These impose many construction difficulties, especially if these barriers are situated in inaccessible hillsides, where construction works require extensive temporary accesses and working platforms (Figure 3). All in all, a holistic revamp in the design approach regarding rigid barriers has been advocated in the geotechnical communities. 
(a)

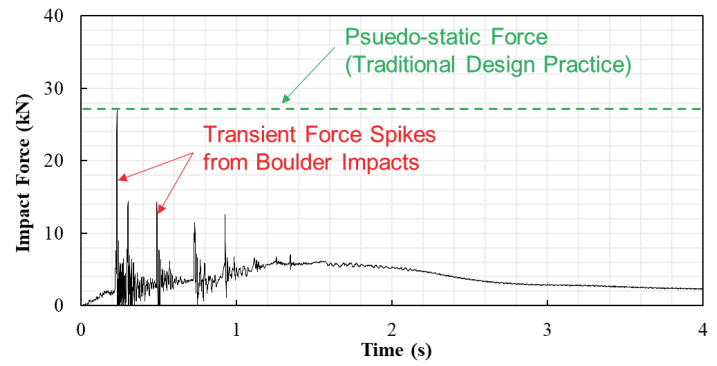

(b)

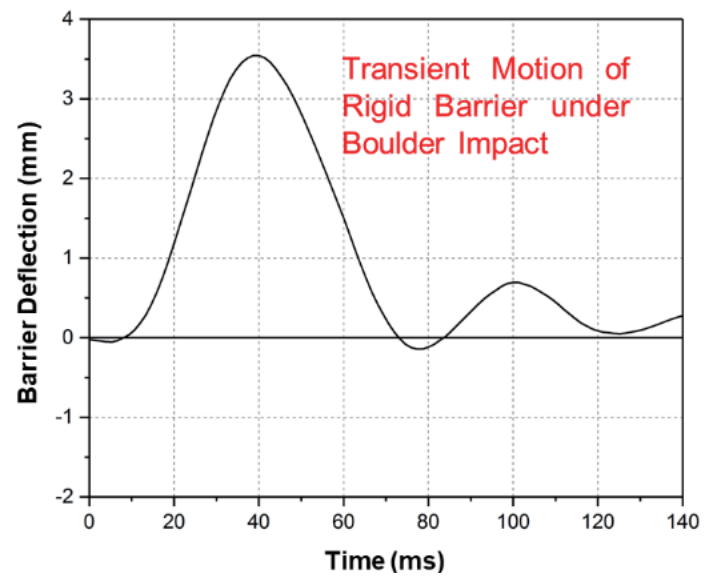

Figure 2. Dynamic nature of boulder impact captured in a flume test of boulder-entrained debris flow (top); tip deflection of wall stem of rigid barrier measured in a boulder impact test using a pendulum setup (bottom).

(a)

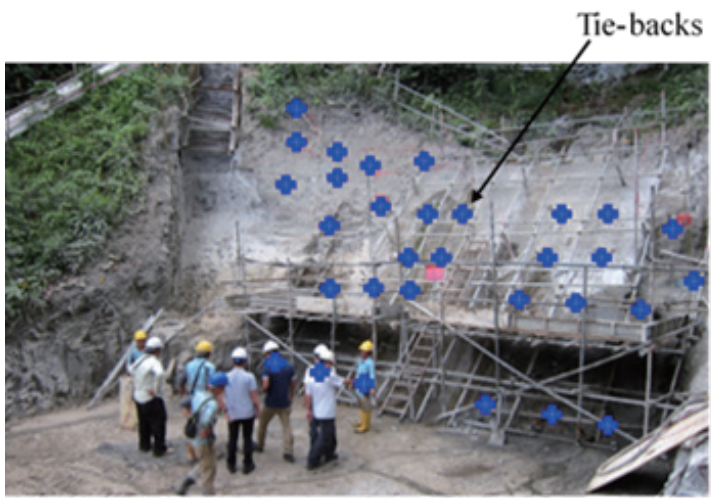

(b)

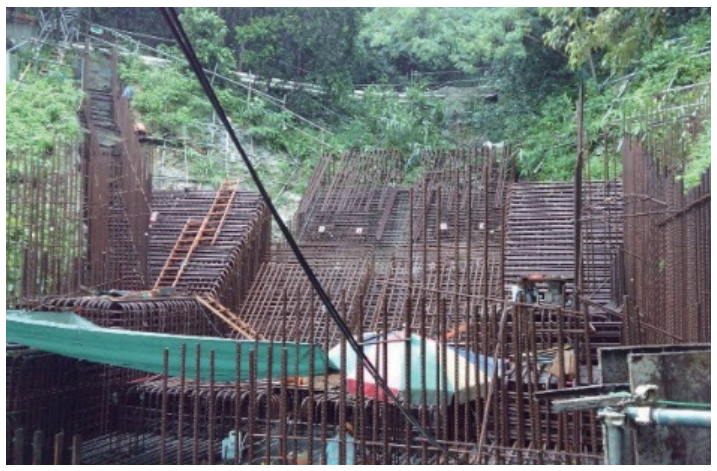

Figure 3. Common construction difficulties of rigid barriers.
The Geotechnical Engineering Office has been endeavouring to enhance the process efficiency in rigid barrier design in Hong Kong. Extensive technical development work with respect to the following technical areas has been conducted:

Area 1. Novel displacement approach for geotechnical stability assessment;

Area 2. Rational assessment of flexure of rigid barriers under boulder impact;

Area 3. Rational use of rockfill gabions as cushioning protection; and

Area 4. Rational estimate of debris impact load.

The above technical areas have been comprehensively studied through a stepwise approach involving analytical modelling, proof-of-concept physical testing and validated numerical parametric studies for extrapolating the scale of analyses. State-of-the-art testing facilities have been used in collaboration with world-leading experts, and some debris impact experiments are of the largest scale as compared with those reported in the literature. The key technical breakthrough includes the optimised debris impact load, introduction of a displacement-based geotechnical stability check and a structural design method which takes into account energy and momentum transfer. A new design framework has been developed and promulgated in the latest design guidance in Hong Kong (GEO, 2020). The key features of the new design framework are summarised in Table 1.

Table 1. Revamping of design framework.

\begin{tabular}{|c|c|c|}
\hline & $\begin{array}{c}\text { Traditional design } \\
\text { framework (Kwan,2012) }\end{array}$ & $\begin{array}{c}\text { Enhanced design } \\
\text { framework (GEO, } \\
\mathbf{2 0 2 0} \text { ) }\end{array}$ \\
\hline \multirow{2}{*}{$\begin{array}{l}\text { Effect of boulder } \\
\text { impact }\end{array}$} & \multirow{2}{*}{$\begin{array}{c}\text { Pseudo-static force } \\
\text { equilibrium analyses } \\
\text { boulder impact load } \\
\text { based on the modified } \\
\text { Hertz model for both } \\
\text { structural integrity check } \\
\text { and geotechnical stability } \\
\text { assessment }\end{array}$} & $\begin{array}{l}\text { Displacement approach } \\
\text { for geotechnical } \\
\text { stability assessment } \\
\text { (Area 1) }\end{array}$ \\
\hline & & $\begin{array}{l}\text { Enhanced Flexural } \\
\text { Stiffness Method for } \\
\text { structural integrity } \\
\text { check (Area 2) }\end{array}$ \\
\hline $\begin{array}{c}\text { Cushioning } \\
\text { protection against } \\
\text { boulder impact }\end{array}$ & Prescriptive & $\begin{array}{l}\text { Reduction in Impact } \\
\text { Load based on 2DOF } \\
\text { Model (Area 3) }\end{array}$ \\
\hline $\begin{array}{l}\text { Debris impact } \\
\text { load }\end{array}$ & $\begin{array}{c}\text { Hydrodynamic equation } \\
\text { with a dynamic pressure } \\
\text { coefficient } \alpha \text { of } 2.5\end{array}$ & $\begin{array}{c}\text { Hydrodynamic } \\
\text { equation with a } \\
\text { dynamic pressure } \\
\text { coefficient } \alpha \text { of } 1.5 \\
\text { (Area 4) }\end{array}$ \\
\hline
\end{tabular}

In Section 2 of this paper, the traditional design framework adopted worldwide, and also in Hong Kong prior to the promulgation of the new design guidance (GEO, 2020), will be introduced, followed by the technical development of the new design framework in Sections 3 to 5. Lastly, the overall savings brought by the new design guidance will be demonstrated in Section 6 . 


\section{Highlights of traditional design practices developed since the 1980s}

\subsection{Background}

In current practice, the design of rigid barriers mainly involves the assessment of geotechnical stability and structural integrity. The traditional static design method is commonly adopted in Hong Kong, and in many regions around the world. Amongst other design loads, the impact loads derived from entrained boulders often control the overall design.

\subsection{Boulder impact load}

Boulder impacts induce large magnitude, transient and localised stress on rigid barriers. The Hertz model, describing the compressive stress generated at the contact of collision of an elastic sphere with an elastic infinite plate, is extensively used to estimate such impact (See Equations 1 and 2). Because of the inherent conservatism of the Hertz model, an empirical load reduction factor $K_{C}$ is usually introduced, which ranges from 0.1 to 0.2 (Hungr et al., 1984; Kwan, 2012; Lo, 2000; PWRI, 1988; Zhou et al., 1991).

$$
F_{b}=K_{c} n\left(\frac{5 m v_{b}{ }^{2}}{4 n}\right)^{0.6},
$$

where $F_{b}$ is the boulder impact force, $K_{C}$ is the load reduction factor (dimensionless), $m$ is the mass of the boulder, $v_{b}$ is the boulder's impact velocity, and $n$ can be calculated by the following equation.

$$
n=\frac{4 r^{0.5}}{3 \pi\left(\frac{1-\mu_{b}{ }^{2}}{\pi E_{b}}+\frac{1-\mu_{B}{ }^{2}}{\pi E_{B}}\right)},
$$

where $r$ is the radius of the boulder, $\mu_{b}$ and $\mu_{B}$ are Poisson's ratio of boulder and barrier, and $E_{b}$ and $E_{B}$ are the modulus of elasticity of boulder and barrier.

The Flexural Stiffness Method (FSM) is also used in some regions (e.g. Zhang et al., 1996; CAGHP, 2018). It assumes that the kinetic energy of the boulder is completely transferred to the barrier as its strain energy. The boulder impact load can be estimated using Equation 3.

$$
F_{b}=v_{b} \sqrt{m k}
$$

where $k$ is the flexural stiffness of the barrier structure.

\subsection{Geotechnical stability assessment}

Limit equilibrium analysis is adopted in the assessment of geotechnical stability of rigid barriers. In essence, a resisting force should be provided to counteract the destabilising impact forces acting on the barriers, such that the static equilibrium in sliding and overturning can be maintained. Resisting force primarily comes from the interface frictional resistance between the barrier and the founding soils or extra structural force given by the tieback foundations.

\subsection{Cushioning protection}

Occasionally large boulders are entrained in a debris flow. To protect rigid barriers against impacts from large boulders, cushioning materials are prescriptively provided. However, this cushioning effect is not quantified in the design in Hong Kong. In overseas practice, the cushioning effect of rockfill gabions in rockfall sheds is established empirically in Japan (JRA, 2000) and Austria (ASTRA, 2008). However, boulder impacts on rockfall sheds involve motion of vertical drops. This renders the direct application of these equations in a rigid barrier design, which involves horizontal impact instead, to be unsuitable.

\subsection{Debris impact load}

In the assessment of debris impact load, hydrodynamic and hydrostatic load models (i.e. Equations 4 and 5 respectively) are widely used in international design standards.

$$
F_{\text {deb }}=\frac{1}{2} K_{\text {static }} \rho g h^{2} w
$$

where $F_{d e b}$ is debris impact force, $K_{\text {static }}$ is dimensionless static pressure coefficient, $\rho$ is debris density, $g$ is gravitational acceleration, $h$ is debris flow depth and $w$ is debris flow width.

$$
F_{d e b}=\alpha \rho v_{d e b}^{2} h w,
$$

where $\alpha$ is dimensionless dynamic pressure coefficient and $v_{d e b}$ is debris impact velocity.

In Hong Kong, a hydrodynamic model with an $\alpha$-value of 2.5 was recommended in the previous design guideline (Kwan, 2012). Debris impact force is estimated using the hydrodynamic model, which is basically the momentum equation in fluid mechanics that is derived from Newton's second law.

\section{Novel displacement approach for geotechnical stability analysis}

\subsection{Background}

Limit equilibrium analyses are more applicable to the static design of structures, e.g. earth-retaining walls, which sustain primarily static loads. The application of traditional static design philosophy on rigid barriers to deal with a momentary boulder impact is not rational. For the design 
of structures under transient seismic loading, displacementbased design has been used extensively in lieu of traditional static limit equilibrium analyses.

Lam et al (2018a) first introduced a displacement approach for the geotechnical stability assessment of rigid barriers in view of the impulsive nature of boulder impacts. Under this approach, if certain movement of a rigid barrier is allowed under a boulder impact scenario, the impact energy can be dissipated through work done against the movement of the barrier and does away the need of provision of unnecessary structural restraints for maintaining the barrier in static equilibrium. In lieu of assessing the factor of safety of a rigid barrier against sliding and overturning, which is a force-based concept for static problems, this analytical approach aims to estimate the induced translational and rotational movement of the barrier ( $\Delta$ and $\theta$ in Figure 4) using Equations 6 to 8. The geotechnical stability of the rigid barrier is ascertained by limiting the barrier displacement. Nevertheless, it has not been verified by means of large-scale impact experiments.

(a)

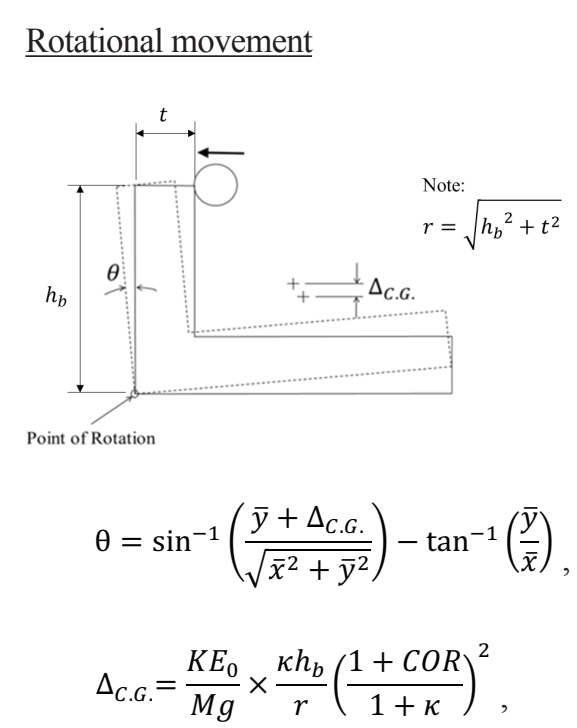

where $h_{b}$ is the height of boulder impact above the point of rotation (equal to the height of wall stem $h z v z$ in the above case involving impact at the crest of the barrier), $t$ is the thickness of the wall stem and $r$ is the distance between the axis of rotation and the point of impact, $\bar{x}$ and $\bar{y}$ are distance to the barrier's centre of gravity measured from the outer edge of the wall stem and the base respectively, $\Delta_{C . G}$. is the rise of the barrier's centre of gravity due to the rotational movement, $K E_{0}$ is kinetic energy of the boulder before impact, and $M$ is the mass of the barrier. In addition, $\kappa$ is equal to $\frac{I_{\theta}}{m h r}$, where $I_{\theta}$ is the mass moment of inertia of the barrier. (b)

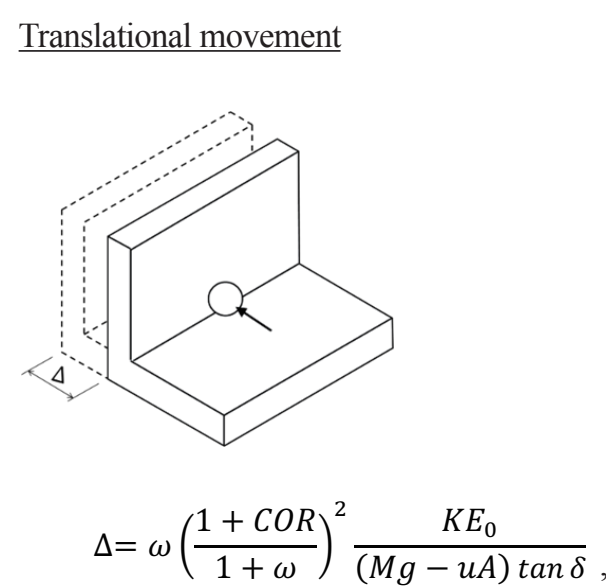

where $\omega$ is the ratio between barrier mass and boulder mass, $u$ is water uplift pressure acting on the barrier, $A$ is the contact area between barrier base and ground surface, $\delta$ is the effective interface friction angle between concrete and its founding materials.

Figure 4. Translational and rotational movement estimated based on displacement approach (Lam and Kwan, 2016).

\subsection{Experimental verification of the displacement approach}

To study the validity of the displacement approach, five large-scale flume tests have been conducted in collaboration with The Hong Kong University of Science and Technology. These tests involved the release of boulders of different sizes from the flume, which produced impacts on a model reinforced concrete barrier. The test programme is summarised in Table 2. The model barrier was an L-shaped reinforced concrete barrier and its dimensions are shown in Figure 5. Details of the setup are discussed in Kwan and Wong (2019).

Table 2. Test programme for verification of displacement approach.

\begin{tabular}{|c|c|c|c|c|}
\hline Test No. & $\begin{array}{c}\text { No. of } \\
\text { boulders }\end{array}$ & $\begin{array}{c}\text { Boulder } \\
\text { diameter }\end{array}$ & $\begin{array}{c}\text { Mass of each } \\
\text { boulder }\end{array}$ & $\begin{array}{c}\text { Observed } \\
\text { Impact } \\
\text { Velocity (m/s) }\end{array}$ \\
\hline $\mathrm{K} 1$ & 1 & $200 \mathrm{~mm}$ & $11 \mathrm{~kg}$ & 7.0 \\
\hline $\mathrm{K} 2$ & 10 & $200 \mathrm{~mm}$ & $11 \mathrm{~kg}$ & 7.0 \\
\hline $\mathrm{K} 3$ & 10 & $400 \mathrm{~mm}$ & $90 \mathrm{~kg}$ & 8.0 \\
\hline $\mathrm{K} 4$ & 1 & $600 \mathrm{~mm}$ & $300 \mathrm{~kg}$ & 6.5 \\
\hline $\begin{array}{c}\text { K5 } \\
\text { (repeat of K4) }\end{array}$ & 1 & $600 \mathrm{~mm}$ & $300 \mathrm{~kg}$ & 6.3 \\
\hline
\end{tabular}

Photographs of the flume tests are shown in Figure 6. The barrier movement based on the displacement approach was predicted using the impact velocity of the boulders and the coefficient of restitution measured using a highspeed camera. The predicted movements in each test have 

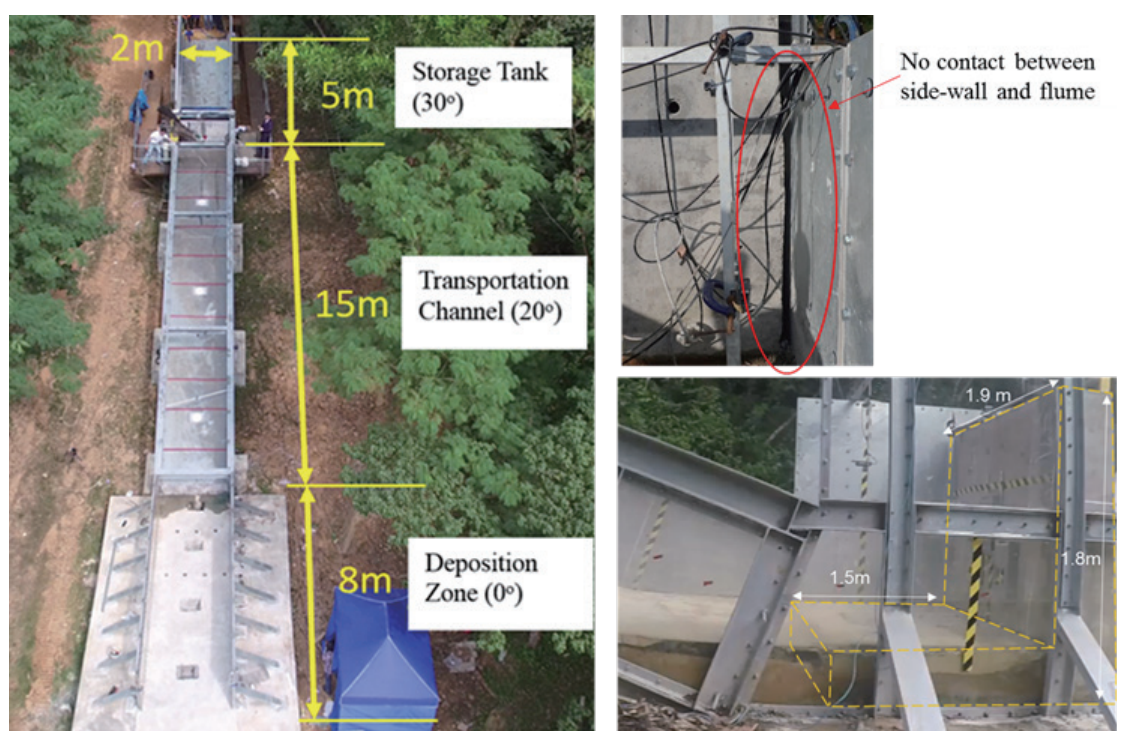

Figure 5. Photograph of flume (left), Front view of model barrier (upper right) and side view of model barrier (lower right).

been compared with the measured movement of the barrier using laser sensors, which showed that the extent of sliding and rotational movements of the barrier predicted by the displacement approach are greater than those observed in the experiments. This is probably due to the fact that the predictions by means of the displacement approach are based on an assumption that the kinetic energy gained by the barrier after impact was dissipated through a specific mode of movement, i.e. either sliding or rotation. In reality, upon an impact, energy dissipation in different modes, e.g. sliding, rotation, structural deformation (e.g. bending, local indentation, internal fracturing), etc. would co-exist. More details of the interpretation of these test results can be found in Wong and Lam (2019b). Based on the experimental results, it was found that the displacement approach produces conservative estimates of barrier displacement.
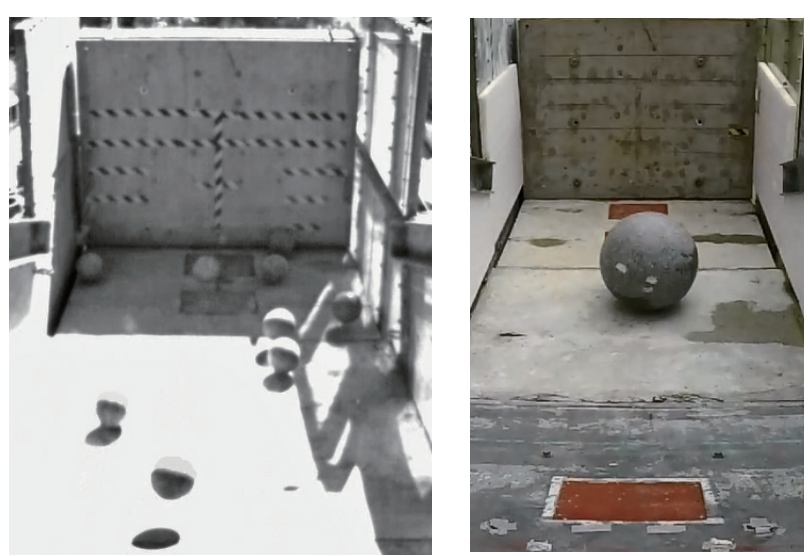

Figure 6. Photographs of Tests K2 and K5.

\subsection{Parametric studies on real-scale impact scenarios}

Two numerical analyses were conducted to simulate impact scenarios involving boulder impact on rigid barriers in real-scale impact scenarios. The analyses aim to overcome the limitations of scale and impact energy in the flume tests above. A validated three-dimensional finite-element computer package namely LS-DYNA was used. Photographs and key outputs of these analyses are given in Figure 7. More details of the numerical analyses are presented in Kwan and Wong (2019). Based on the comparison, it was found that the displacement approach can generally provide conservative estimates of a barrier's movement as compared with the outputs of numerical simulations. For a barrier with a sufficient mass, translational and rotational movements are deemed to be insignificant for typical boulder impact scenarios and, thus displacement check is generally not necessary (GEO, 2020).

(a)

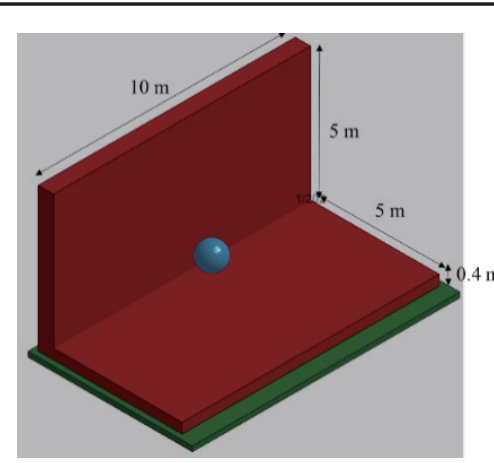

Model No. LS

Translational movement

$1.3 \mathrm{~mm}$ (from LS-DYNA simulation)

$1.4 \mathrm{~mm}$ (from displacement approach) 
(b)

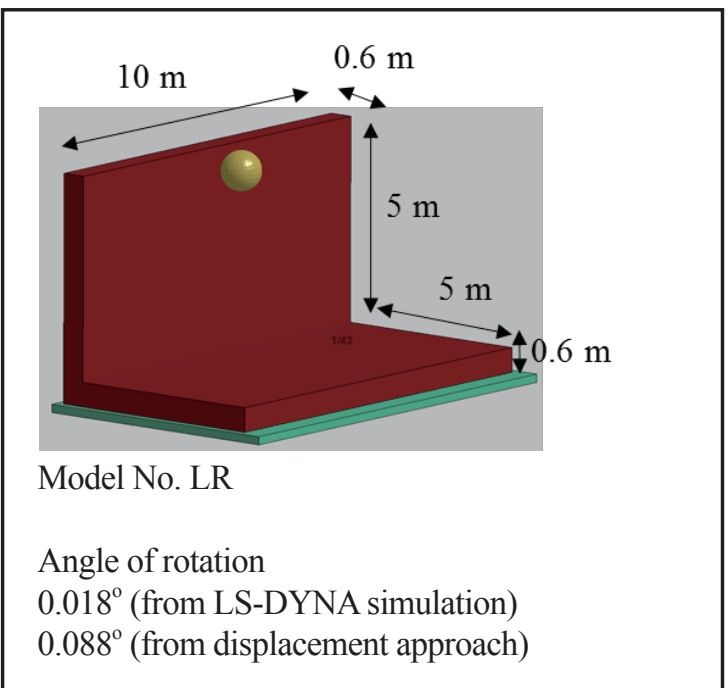

Figure 7. Results of numerical parametric studies on the displacement approach.

\section{Rational assessment of flexure of a rigid barrier under boulder impact}

\subsection{Background}

In the structural design of rigid barriers, an assessment of boulder impact force is required (see Section 2.2). Lam and Gad (2016) introduced the Enhanced Flexural Stiffness Method (EFSM) for estimating the impact load in vehicular collision as given in Equations 9 and 10. EFSM goes a step further than FSM (i.e. Equation 3) by considering the conservation of momentum as well as the energy loss during an impact. An analytical energy reduction factor $\beta$ is introduced.

$$
\begin{aligned}
& F_{b}=\beta v_{b} \sqrt{m k}, \\
& \beta=\sqrt{\lambda\left(\frac{1+C O R}{1+\lambda}\right)^{2}},
\end{aligned}
$$

where COR is coefficient of restitution between boulder and barrier, and $\lambda$ is the ratio between the participating mass (i.e. one quarter of the mass of the wall stem) of the barrier and boulder mass, which should be greater than unity.

\subsection{Experimental verification of the Enhanced Flexural Stiffness Method}

In view of the potential applicability of EFSM to the structural design of a rigid barrier, 28 large-scale impact tests were conducted, in collaboration with the University of Melbourne. An inverted T-shaped model rigid barrier was constructed for the study (see Figure 8). Detailed setup of the model barrier is given in Lam et al (2018b). (a)

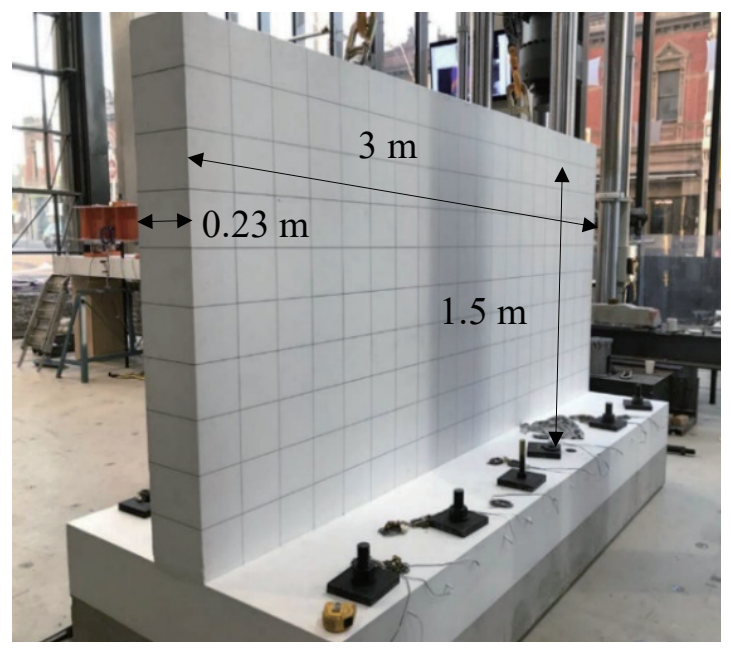

(b)

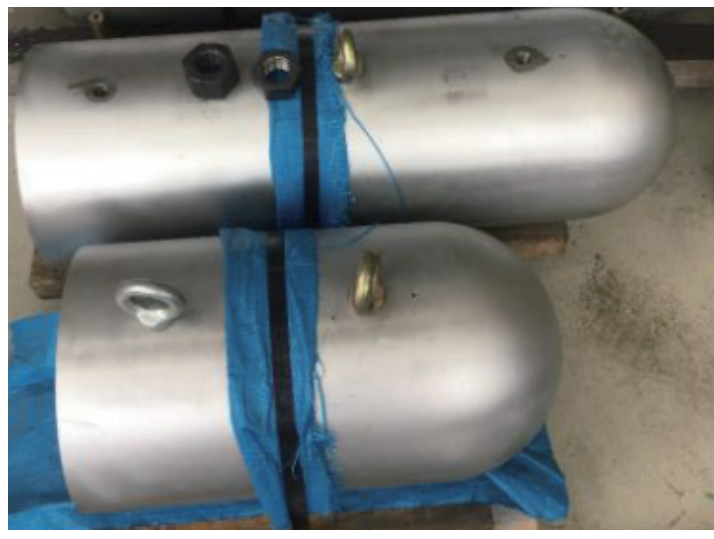

Figure 8. Photographs showing the model barrier and the solid steel impactors SS280 and SS435.

In each impact test, an impactor was used to produce a strike to the wall stem of the model barrier using a pendulum setup. In the first series of tests, two different steel impactors, weighing $280 \mathrm{~kg}$ and $435 \mathrm{~kg}$, were used (see Figure 8). In the second series of tests, four different natural boulders were used as impactors (see Figure 9).

A high-speed camera and laser sensors were adopted to capture the impact velocity of the impactor and the deflection profile of the wall stem of the model barrier. Strain gauges were installed on the concrete surface of the wall stem and the vertical reinforcement bars for the measurement of the concrete and steel strains.

The main objective of these impact tests is to verify EFSM in different impact scenarios. A photograph taken in one of these tests and a typical deflection time-history of the crest of the model barrier are given in Figure 10. In these impact tests, EFSM consistently provides close estimates of flexural response of the model barrier in various impact scenarios. More details of the experiments are given in Wong and Lam (2018b and 2019a). 


\begin{tabular}{|c|c|c|c|c|c|}
\hline \multicolumn{2}{|c|}{ Impactor G-B } & \multicolumn{2}{|c|}{ Impactor VB } & Impactor G-1 & Impactor G-2 \\
\hline Impactor & Rock type & Mass (kg) & $\begin{array}{l}\text { Young's modulus } \\
\text { (GPa) }\end{array}$ & $\begin{array}{c}\text { Uniaxial compressive } \\
\text { strength }(\mathrm{MPa})\end{array}$ & $\begin{array}{c}\text { Longest } \\
\text { dimensions }(\mathrm{mm})\end{array}$ \\
\hline G-B & Granite & 315 & 49.1 & 113 & 612 (Diameter) \\
\hline VB & Volcanic & 155 & 5.5 & 26 & 670 (Side AB) \\
\hline G-1 & Granite & 220 & 19.1 & 59 & 800 (Side AB) \\
\hline G-2 & Granite & 200 & 94.4 & 101 & 650 (Side CD) \\
\hline \multicolumn{6}{|c|}{$\begin{array}{l}\text { Note: The Young's modulus and uniaxial compressive strength were obtained from laboratory tests on the rock core } \\
\text { retrieved from each boulder after the impact tests. }\end{array}$} \\
\hline
\end{tabular}

Figure 9. Boulder impactors G-B, VB G-1 and G2.

(a)

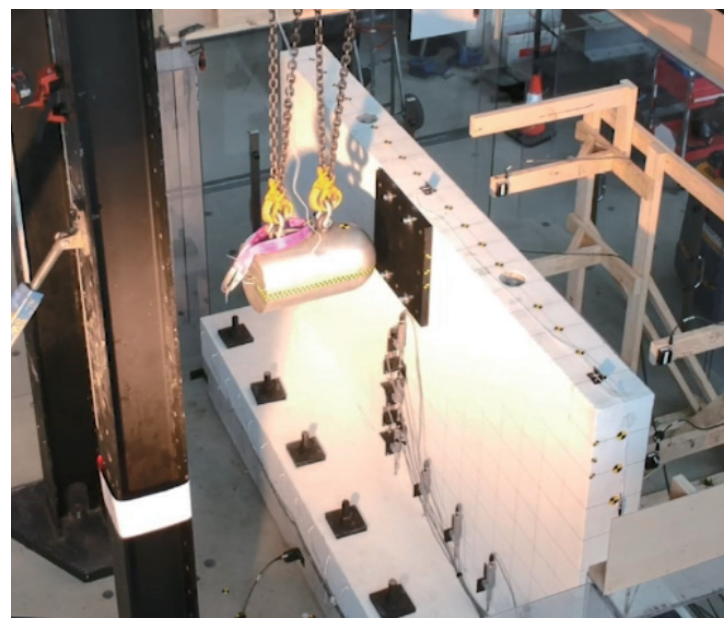

(b)

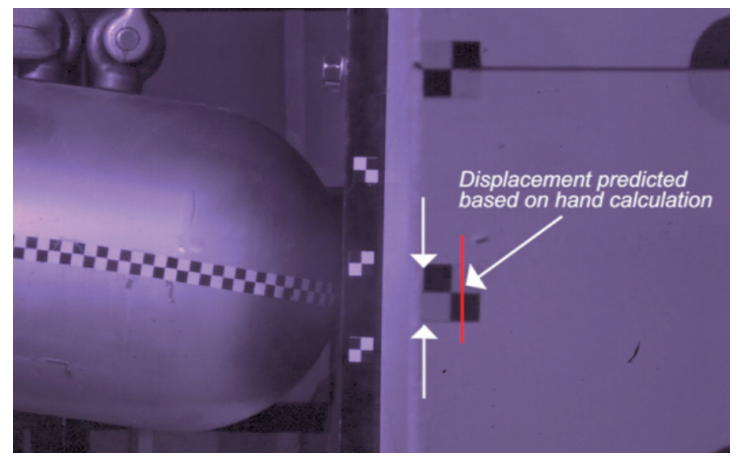

(c)

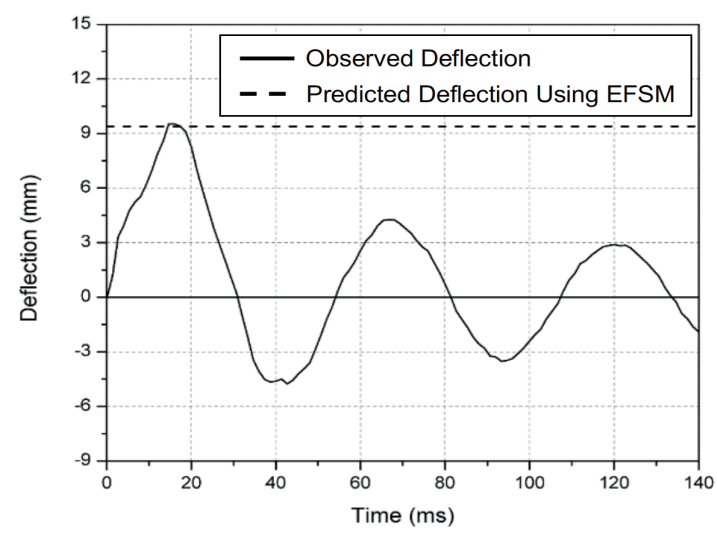

Figure 10. Impact test for verification of EFSM and a test result (deflection-time history of model barrier).

\subsection{Numerical study of the Enhanced Flexural Stiffness Method}

To further verify EFSM, numerical analyses were conducted systematically using the commercially available LS-DYNA programme. These analyses aimed to assess the behaviour of a rigid barrier under impact scenarios which are similar to real-scale landslide case histories (up to $470 \mathrm{~kJ}$ ). The numerical model had been validated using published large-scale impact experiments on reinforced concrete structures (details in Wong and Lam, 2018a).

Figure 11 shows two numerical parametric studies on the effect of the boulder impact velocity and the size of boulder on the flexural response of the rigid barrier, which indicate that EFSM produces more a realistic prediction than the traditional design methods (i.e. Equations 1 to 3 ). 
(a)

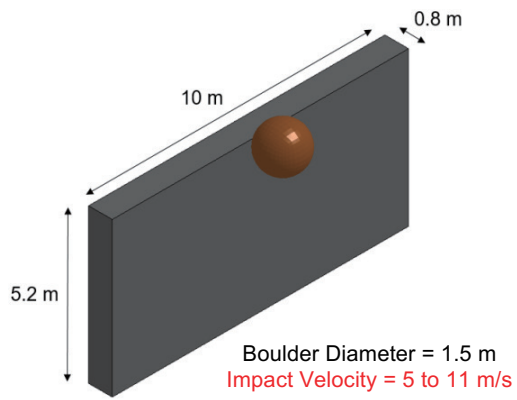

Parametric study series No. 1 - Effect of boulder impact velocity on flexural response of barrier

(b)

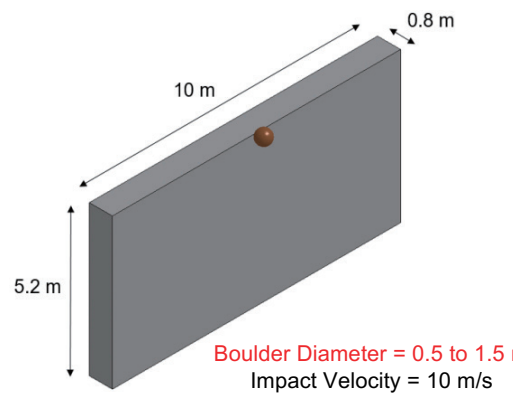

Parametric study series No. 2 - Effect of impacting boulder size on flexural response of barrier

(c)

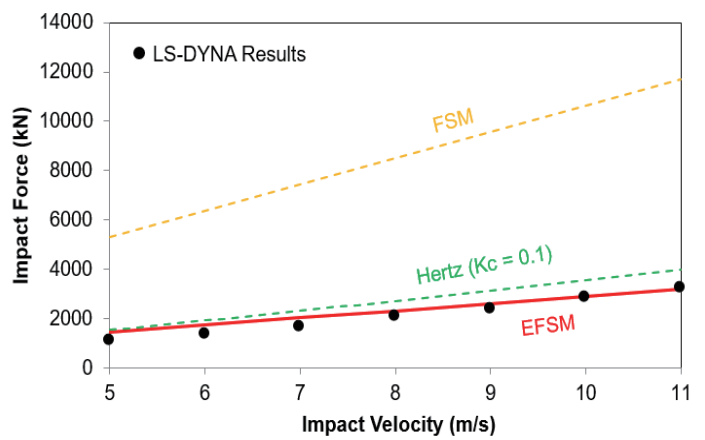

Comparison of FSM, EFSM, Hertz model and numerical simulations

(d)

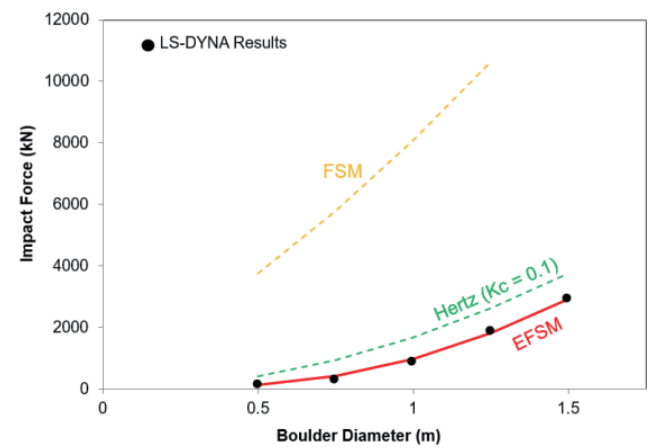

Comparison of FSM, EFSM, Hertz model and numerical simulations

Figure 11. Numerical parametric studies for verification of EFSM (Wong and Lam, 2018a: p.12-13).

\section{Optimisation of structural design through rational use of rockfill gabions as cushioning protection}

\subsection{Background}

As shown in the bottom-right chart in Figure 11, the flexural response of a rigid barrier increases non-linearly with the size of the boulder. As a result, barriers subjected to large boulder impacts have to be designed with a thicker wall section and with congested steel reinforcements. Alternatively, cushioning materials could be used to reduce the impact load acting on the rigid barrier. Rockfill gabions cushion is one of the commonest types of cushioning material (see Figure 12), and can dissipate impact energy as a result of deformation of rockfill.

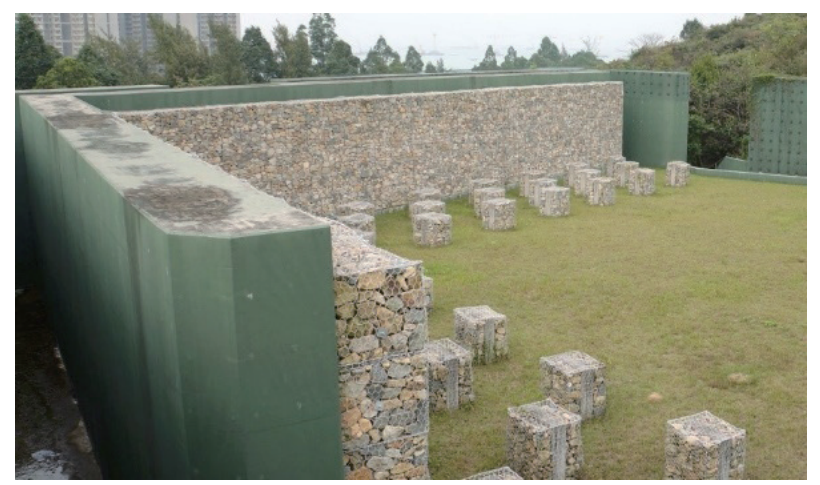

Figure 12. Use of rockfill gabions cushion to protect a rigid barrier.

\subsection{Experimental study of cushioning protection}

To quantitatively examine the cushioning ability of rockfill gabions, four series of large-scale impact tests on model cushioned rigid barriers were conducted. The first two series of tests involved $500 \mathrm{~mm}$ thick gabions infilled with 70 to $100 \mathrm{~mm}$ diameter crushed granite cobbles. Steel impactors of $280 \mathrm{~kg}$ and $435 \mathrm{~kg}$ were used and the impact velocity ranged from $2.51 \mathrm{~m} / \mathrm{s}$ to $5.24 \mathrm{~m} / \mathrm{s}$. The model barrier had the same dimensions as that adopted in Section 4.2. In the remaining two series of tests, spherical concrete impactor of $1961 \mathrm{~kg}$, involving a higher impact velocity $(4.5 \mathrm{~m} / \mathrm{s}$ to $8.4 \mathrm{~m} / \mathrm{s})$ was adopted. A stiffer model barrier of $3 \mathrm{~m}$ wide $\times 1.5 \mathrm{~m}$ high $\times 1.5 \mathrm{~m}$ thick with $1 \mathrm{~m}$ thick rockfill gabion cushion was adopted in these two tests. Photographs of the two series of impact tests are given in Figure 13 below. These impact tests provided quality data for the further analytical study of the cushioning response of rockfill gabions. 


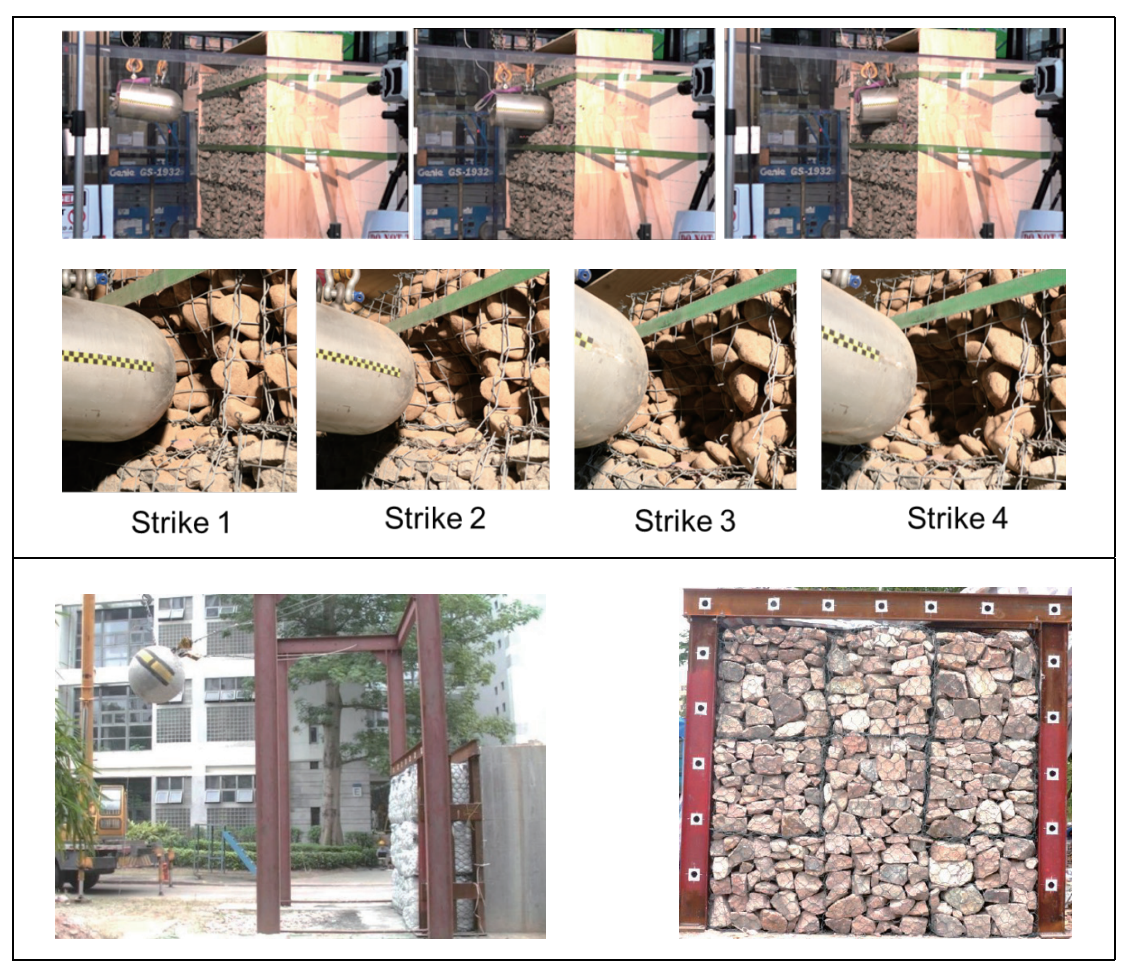

Figure 13. Photographs of two series of large-scale impact tests of cushioned rigid barriers (Lam, 2016; Wong and Lam, 2019a: p.22-23).

\subsection{Two degree-of-freedom lumped mass (2DOF) system based on viscos-elastic contact model}

An analytical model to predict the contact force and flexural response generated during a collision has been developed by Sun et al (2014). This model adopts a springconnected two degree-of-freedom lumped mass (2DOF) system (see Figure 14) that can capture the time histories of the contact force of an impactor, indentation and the global flexural response of a barrier in an integrated manner. The contact process in the 2DOF system is assumed to be simulated by a damper and a spring based on the viscoelastic contact model developed by Hunt and Crossley (1975). The damper is to allow for energy dissipation in the cushioned layer in the vicinity of the contact area during the impact process, which includes plastic deformation of the cushion, work done on re-arrangement of rockfill particles, etc. Wong and Lam (2019c) further proposed a modification in the estimation of the contact spring stiffness in 2DOF model. Governing equations of the 2DOF model are as follows:

$$
\begin{aligned}
& F_{c}(t)=k_{1} \delta(t)+D_{1} \delta(t) \dot{\delta}(t), \\
& F_{c}(t)=m_{2} a_{2}(t)+k_{2} x_{2}(t),
\end{aligned}
$$

where $F_{c}(t)$ is contact force-time history between the boulder and lumped mass of cushion-barrier, i.e. force at contact spring in Figure 14, k1 is contact spring stiffness, $\delta(t)$ is shortening of contact spring (i.e. the movement of the centre of the boulder resulting from both compression of the boulder and indentation into the surface of the barrier), D1 is damping coefficient, $\dot{\delta}(t)$ is rate of shortening of contact spring, $\mathrm{m} 2$ is lumped mass of cushioned barrier wall stem, $\mathrm{a}_{2}(\mathrm{t})$ is acceleration of cushion-barrier lumped mass, $\mathrm{k} 2$ is rear spring stiffness, i.e. cracked flexural stiffness of the rigid barrier, $\mathrm{x}_{2}(\mathrm{t})$ is flexural deflection of the crest of the rigid barrier.

(a)

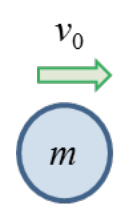

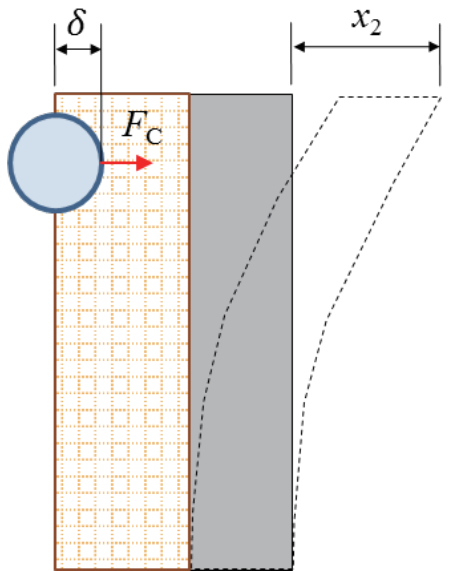

Impact scenario 
(b)

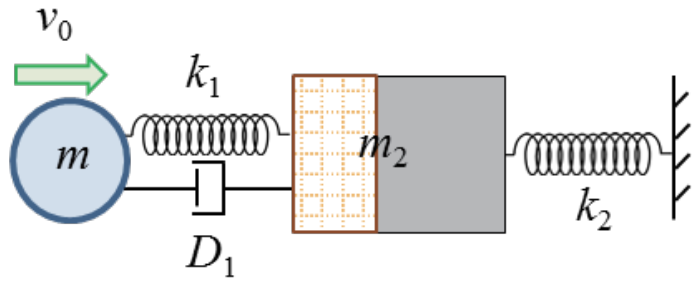

Idealised scenario

Figure 14. 2DOF Spring Mass System utilising Hunt and Crossley Model.

The visco-elastic model is a non-linear contact model with a hysteresis loop in force-displacement space. The area under the hysteresis loop represents the strain energy absorption by the gabion cushion materials. Details of the analytical model are discussed in Wong and Lam (2019c).

To assess the applicability of the $2 \mathrm{DOF}$ model in a rigid barrier design, the $2 \mathrm{DOF}$ model has been used to estimate the model barrier's response under the impact tests discussed in Section 5.2. It was found that the predicted barrier's response based on 2DOF analyses, in terms of peak barrier deflection, were generally comparable to the test results. An example of comparison is given in Figure 15 below.

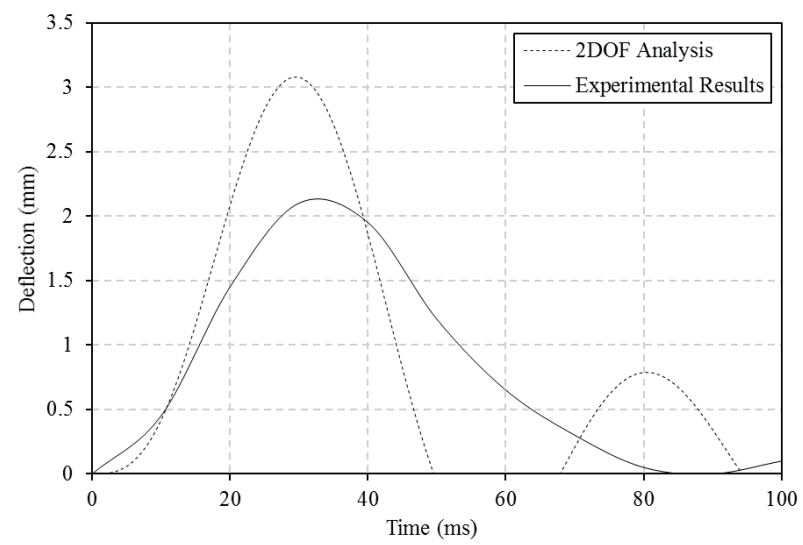

Figure 15. Comparison of measured deflection-time history and predicted deflection-time history based on 2DOF analysis (Wong and Lam, 2019c: p.12).

In the derivation of the $2 \mathrm{DOF}$ model, the rigid barrier is assumed to be a cantilever wall. In other words, energy loss due to global displacements (i.e. translational and rotational movements) of the barrier are neglected. In reality, the impact energy of the boulder converts to different sources of energy of the barrier. The problem of energy partitioning is complex and the above assumption ensures that the boulder impact force so calculated will not be underestimated.

\subsection{Parametric studies on real-scale impact scenarios}

To assess the amount of reduction in impact load in real-scale impact scenarios, a series of parametric studies of the cushioning effect was conducted using the validated 2DOF model. The boulder impact scenarios adopted are those commonly encountered in routine designs in Hong Kong (e.g. impact velocity and diameter of the boulder, dimensions and reinforcement contents of the rigid barrier and thickness of rockfill gabions cushion). Based on the sensitivity studies, it was found that the flexural response of the rigid barrier in routine design scenarios (i.e. estimated using EFSM, also see Section 4) can be further optimised by approximately $35 \%$. Direct use of the 2DOF model is not straightforward since it requires some parameters obtained from physical experiments, e.g. back-calculation of parameters k1 and D1 from impact tests data. As such, as a simplification in the enhanced design guidance, designers can estimate the boulder impact load using EFSM, and apply a $35 \%$ load reduction factor if a minimum of 500 $\mathrm{mm}$ thick rockfill gabion cushion is provided. More details on the model validations and parametric studies above are given in Wong and Lam (2019c).

\section{Optimisation of debris impact load}

\subsection{Background}

Various technical development works have been conducted to study the debris impact load models. In the hydrostatic model, the suggested $K_{\text {static }}$-value ranges from 2.5 to 7.5 (e.g. Armanini et al., 2019; Scotton and Deganutti, 1997). In the hydrodynamic model, the $\alpha$-value ranges from 0.4 to 12 (e.g. ASI, 2013; Bugnion et al., 2012; CAGHP, 2018; Daido, 1993; Hungr et al, 1984; Kwan, 2012; Lo, 2000; MLR, 2006; NILIM, 2007; SWCB, 2019; Watanabe and Ikeya, 1981; Zhang, 1993 ). Song et al. (2021a; 2021b) showed that the debris impact load is a function of the dimensionless Froude number. Some practitioners suggest a hybrid of hydrodynamic and hydrostatic model in estimating the debris impact pressure (e.g. Li et al., 2020).

Early studies of the hydrodynamic model reported large $\alpha$-values of 2.5 and 3 (e.g. Du et al, 1987), which aims to account for debris impact with an allowance of boulder impact load. Wong and Lam (2019d) suggested to assess the debris and boulder impact separately, taking due account of the more transient nature of boulder impact as compared with that of debris.

\subsection{Experimental study of debris impact lad}

To study debris impact load, a series of large-scale flume tests have been conducted using the flume setup and reinforced concrete model barrier as described in Section 
3.2. The scale of the simulated debris flow was less than $5 \mathrm{~m} 3$. To capture the overall debris impact load, a special setup comprising a series of load cells and a steel plate, as shown in Figure 16. This setup avoids the extrapolation of impact load based on the measurement of localised pressure taken from a small load cell. Details of these tests, including setup, instrumentation, test results and data interpretation, have been discussed in Lam and Wong (2021). Photographs of two of the tests involving pure debris flow and boulder-entrained debris flow are shown in Figure 17. By discounting the effect of boulder hard inclusions, the peak $\alpha$-value was found, ranging from 0.76 to 1.01 .

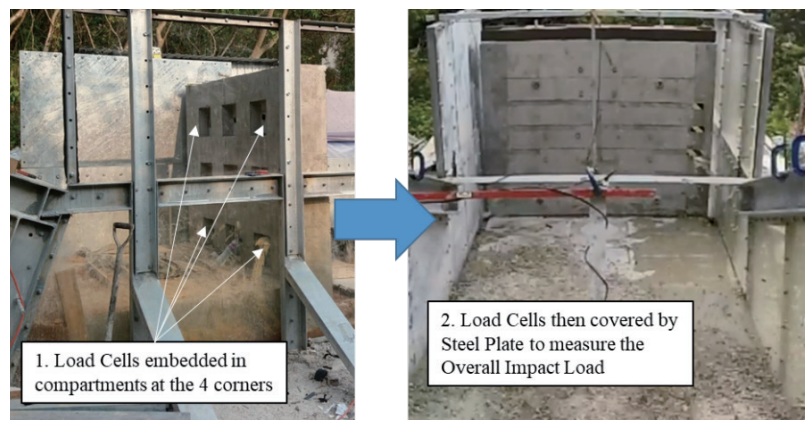

Figure 16. Setup for debris impact load measurement in large-scale flume tests.
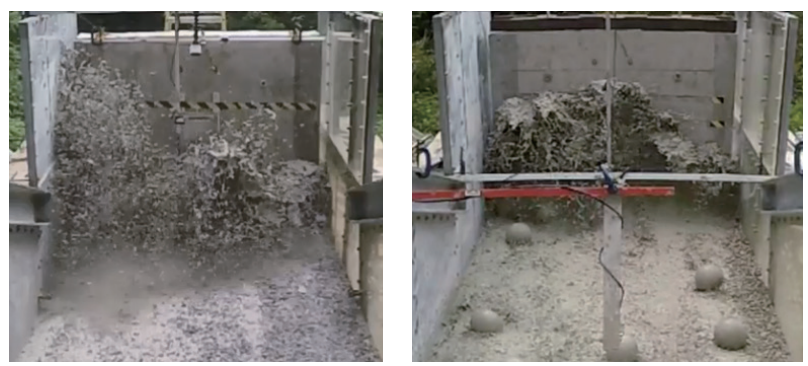

Figure 17. Simulated debris flow (Left) and boulderentrained debris flow with 30 model boulders $200 \mathrm{~mm}$ in diameter.

\subsection{Numerical analysis}

To overcome the scale-effect associated with the flume tests and to further assess the debris impact load for design events typically encountered in Hong Kong in the order of a hundred square metres, numerical analysis was conducted using LS-DYNA. Debris materials are simulated using the Arbitrary Lagrangian-Eulerian technique. The internal rheology and debris-barrier interaction has been validated against the data of flume test conducted. A photograph of the validation is shown in Figure 18.

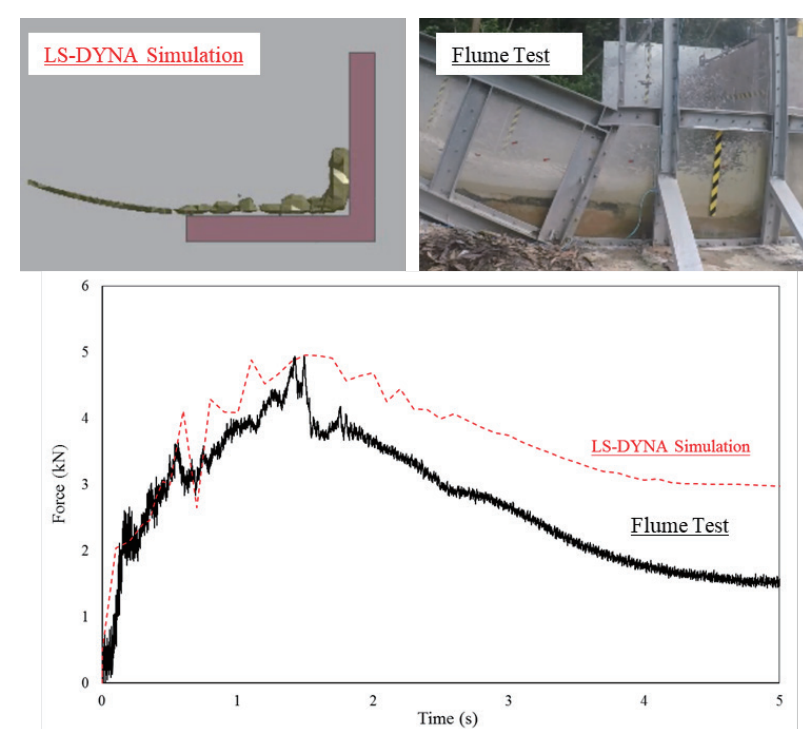

Figure 18. Validation of numerical simulation of debrisbarrier interaction using large-scale flume test data.

Using the rheology parameters for debris and material models of reinforced concrete, a large-scale debris flow event with a debris volume of approx. $400 \mathrm{~m}^{3}$, travelling at a frontal flow velocity of $12 \mathrm{~m} / \mathrm{s}$ and a debris flow thickness ranging from 1.25 to $1.5 \mathrm{~m}$, was simulated to impact onto a reinforced concrete barrier of $10 \mathrm{~m}$ wide, $5 \mathrm{~m}$ high and 1 $\mathrm{m}$ thick. Based on the output debris mobility data and the impact pressure on the model barrier from the LS-DYNA model (see the photographs in Figure 19), the $\alpha$-value is found to be 0.97 .
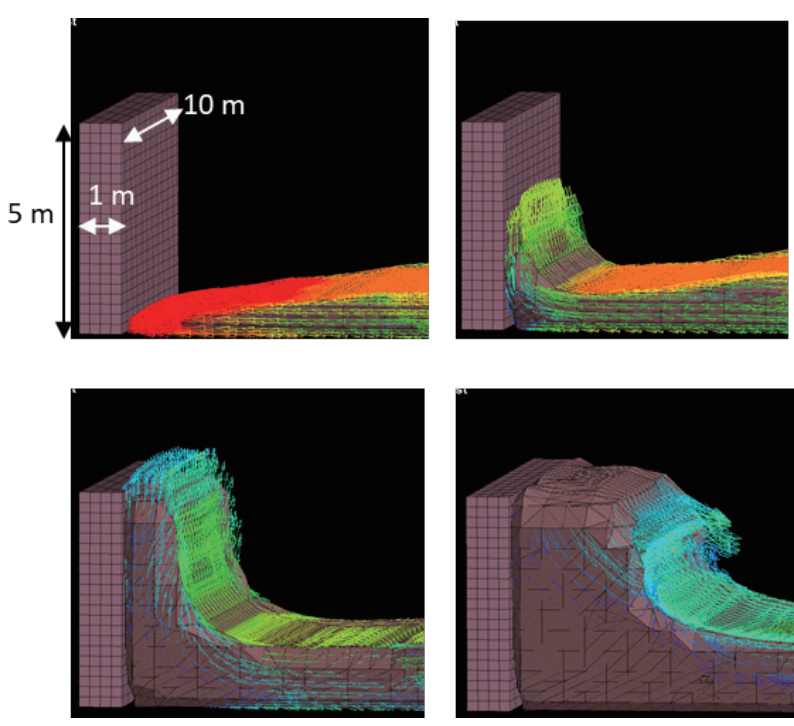

Figure 19. Photograph of debris impact scenario in a 400 $\mathrm{m}^{3}$ volume simulated design event. 


\subsection{Discussions}

Based on the experimental results, numerical analyses and some latest overseas design guidelines (e.g. ASI, 2013; CAGHP, 2018; MLR, 2006; NILIM, 2007), there is room to optimise the $\alpha$-value from 2.5 to 1.5 .

In the enhanced design guidance, the effect of boulder impact is not taken into account in the hydrodynamic equation with a larger $\alpha$-value. Boulder impact is more transient than debris impact, and the effect of the flexural stiffness and mass ratio of the barrier are key factors affecting the boulder impact load, whereas these factors are less critical in debris impact. It is thus suggested that the effect of boulder impact should be considered separately using the displacement approach in geotechnical stability analysis and EFSM in structural design.

\section{Discussions on the improvement of the enhanced design guidance}

This section explains a design of rigid barrier which follows both (a) the previous generation of guidelines (Kwan, 2012) as well as (b) the enhanced design guidance (GEO, 2020). The rigid barrier is subjected to a design debris flow event, which comprises entrainment of 1 $\mathrm{m}$ diameter boulders, travelling in surges at an impact velocity ranging from 4.9 to $7.0 \mathrm{~m} / \mathrm{s}$ according to debris mobility analysis. Barrier design following (a) and (b) is summarised in Figure 20 below:

(a)

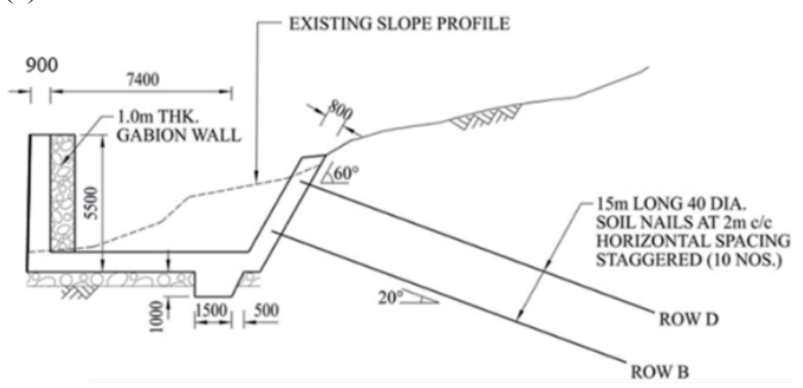

(b)

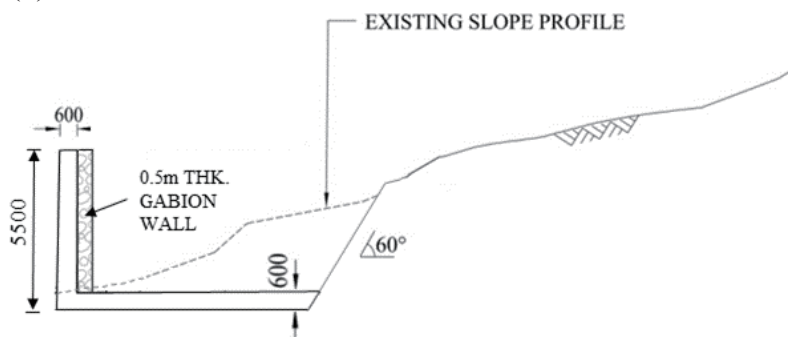

Figure 20. Design following (a) the previous design guidance (top) and (b) the enhanced design guidance (bottom).
As shown above, tieback foundations are no longer necessary as a small amount of displacement is allowed under the displacement approach. In addition, rational use of rockfill gabions cushion alongside the novel EFSM enable an optimisation of the structural design of the barrier, giving rise to a saving of $30 \%$ by volume of concrete, and also $30 \%$ by weight of steel reinforcements.

\section{Summary}

As presented in Sections 3 to 6 above, a novel design approach for geotechnical stability and structural integrity assessment of rigid barriers has been developed. The transient nature of boulder impacts and the dynamic response of rigid barriers have been duly addressed. The enhanced design approach has been well proven by experimental and numerical simulations. It involves simple analytical solutions, which are easy to implement in practice. It would bring more cost-effective and lean barrier designs, with enhanced design robustness and reliability. The enhanced design guidance has been promulgated in 2020 for practical use in Hong Kong.

\section{Acknowledgement}

This paper is published with the permission of the Head of the Geotechnical Engineering Office and the Director of Civil Engineering and Development, the Government of the Hong Kong Special Administrative Region.

\section{Notes on contributor}

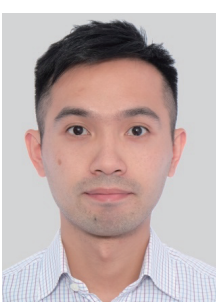

Ir Anthony L Wong is a Geotechnical Engineer in the Geotechnical Engineering Office (GEO), Civil Engineering and Development Department. He obtained his B.Eng. degree from The University of Hong Kong. He was awarded Young Innovator Prize for the Construction Innovation Award 2019 by the Construction Industry Council, and Grand Prize for the HKIE Innovation Awards for Young Members 2019. Currently, he is responsible for the technical development of natural terrain risk mitigation measures and ground improvement work in Hong Kong. 


\section{References}

[1] Armanini A, Rossi G and Larcher M (2019). Dynamic impact of a water and sediments surge against a rigid wall. Journal of Hydraulic Research, 58(2), pp. 314325.

[2] ASI (2013). ONR 24801 Protection Works for Torrent Control - Static and Dynamic Actions on Structures. Austrian Standard Institute, Austria.

[3] ASTRA (2008). Einwirkungen infolge Steinschlags auf Schutzgalerien, Richtlinie (Effects of Rockfall on Protection Galleries, Guideline). Bundesamt für Strassen ASTRA (Federal Roads Office), Switzerland.

[4] Bugnion L, McArdell BW, Bartelt P and Wendeler C (2012). Measurements of hillslope debris flow impact pressure on obstacles. Landslides, 9(2),pp.179-187.

[5] CAGHP (2018). Specification of Design for Debris Flow Prevention (T/CAGHP 021-2018). China Association of Geological Hazard Prevention.

[6] Daido A (1993). Impact force of mud debris flows on structures. XXV IAHR Congress, Tokyo, Japan, pp.211-213.

[7] Du R, Kang Z, Chen X and Zhu P (1987). A comprehensive investigation and control planning for debris flow in the Xiaojiang River Basin of Yunnan Province. Science Press.

[8] GEO (2020). Enhanced Technical Guidance on Design of Rigid Debris-resisting Barriers (GEO Technical Guidance Note No. 52).

[9] Hungr O, Morgan GC and Kellerhals R (1984). Quantitative Analysis of Debris Torrent Hazards for Design of Remedial Measures. Canadian Geotechnical Journal, 21:pp.663-677.

[10] Hunt KH and Crossley FRE (1975). Coefficient of restitution interpreted as damping in vibroimpact. Journal of Applied Mechanics, 1975, 42(2): p. 440.

[11] JRA (2000). Manual for anti-impact structures against falling rock (in Japanese). Japan Road Association, Japan.

[12] Kwan JSH (2012). Supplementary Technical Guidance on Design of Rigid Debris-resisting Barriers (GEO Report No. 270). Geotechnical Engineering Office, Hong Kong.

[13] Kwan JSH and Wong LA (2019). A new generation of rigid debris-resisting barriers system in Hong Kong. Proceedings of IPL Symposium, UNESCO, Paris, pp.7-14.

[14] Lam C (2016). A Pilot Study of the Use of Cushioning Materials for Reducing Dynamic Impact Loads on Rigid Debris-resisting Barriers (Technical Note No. TN 5/2016). Geotechnical Engineering Office, Hong Kong.

[15] Lam C and Kwan JSH (2016). Displacement-based Assessment of Boulder Impacts on Rigid Debrisresisting Barriers - A Pilot Study (GEO Technical Note No. 9/2016). Geotechnical Engineering Office, Hong Kong.
[16] Lam C, Yong ACY, Kwan JSH and Lam NTK (2018a). Overturning stability of Lshaped rigid barriers subjected to rockfall impacts. Landslides, 15(7): pp.1347-1357.

[17] Lam NTK, Yong ACY, Perera JS, Kwan JSH, Lam HWK and Wong LA (2018b). Flexural Response of Reinforced Concrete Barriers subject to Boulder Impact. Proceedings of ISSMGE Second JTC1 Workshop - Triggering and Propagation of Rapid Flow-like Landslides.

[18] Lam HWK and Wong LA (2021). Experimental and numerical study of dynamic soil debris impact load on reinforced concrete debris-resisting barriers. Landslides 18, pp. 955-966.

[19] Lam N and Gad E (2016). The estimation of impact forces based on first principles. In Australasian Structural Engineering Conference: ASEC 2016, Engineers Australia.

[20] Lo DOK (2000). Review of natural terrain landslide debris-resisting barrier design (GEO Report No. 104). Geotechnical Engineering Office, Hong Kong.

[21] MLR (2006). Specification of geological investigation for debris flow stabilization. National Land Resources Department, China.

[22] NILIM (2007). Manual of technical standard for designing sabo facilities against debris flow and driftwood. Ministry of Land, Infrastructure and Transport, Japan, 73p.

[23] PWRI (1988). Technical standard for the measures against debris flow (Draft). Public Works Research Institute, Japan.

[24] Scotton P and Deganutti AM (1997). Phreatic line and dynamic impact in laboratory debris flow experiments. 1st ASCE Intl conference on debris flow hazard mitigation. San Francisco, USA, pp.777-786.

[25] Song D, Chen XQ, Zhou GGD, Lu X, Cheng G and Chen Q (2021a). Impact dynamics of debris flow against rigid obstacle in laboratory experiments. Engineering Geology 291.

[26] Song D, Zhou GGD, Chen XQ, Lie J, Wang A, Peng P and Xue KX (2021b). General equations for landslide-debris impact and their application to debrisflow flexible barrier. Engineering Geology 288.

[27] Sun J, Lam N, Zhang L, Gad E and Ruan D. (2014). Contact forces generated by fallen debris. Structural Engineering and Mechanics, 2014, 50(5): pp. 589603.

[28] SWCB (2019). “Debris-flow Chapter” in Soil and Water Conservation Handbook. Soil and Water Conservation Bureau, Taiwan.

[29] Watanabe M and Ikeya H (1981). Investigation and analysis of volcanic mud flows on Mount Sakurajima, Japan. Erosion sediment transport measurement.: Int Assoc Hydrol Sei Publ 133: pp.245-256. 
[30] Wong LA and Lam HWK (2018a). Study of Flexural Response of Rigid Barriers Subject to Boulder Impact (GEO Technical Note No. 3/2018). Geotechnical Engineering Office, Hong Kong.

[31] Wong LA and Lam HWK (2018b). Large-scale Experimental Study of Structural Response of Rigid Barriers Subject to Hard Impacts (GEO Technical Note No. 7/2018). Geotechnical Engineering Office, Hong Kong.

[32] Wong LA and Lam HWK (2019a). Supplementary Experimental Study of Structural Response of Rigid Barriers subject to Hard Impacts (GEO Technical Note No. 3/2019). Geotechnical Engineering Office, Hong Kong.

[33] Wong LA and Lam HWK (2019b). Verification of Displacement-Approach for Rigid Debris-resisting Barriers subject to Boulder Impacts (GEO Technical Note No. 4/2019). Geotechnical Engineering Office, Hong Kong.

[34] Wong LA and Lam HWK (2019c). Analytical Study of Cushioning Effect Provided by Rockfill Gabions in Reducing Flexural Response of Rigid Barriers subject to Boulder Impacts (GEO Technical Note No. 6/2019). Geotechnical Engineering Office, Hong Kong.

[35] Wong LA and Lam HWK (2019d). Study of dynamic soil debris impact load on rigid debrisresisting barriers (GEO Technical Note No. 5/2019). Geotechnical Engineering Office, Hong Kong.

[36] Zhang S, Hungr O and Slaymaker O (1996). The calculation of impact force of boulders in debris flow. Debris Flow Observation and Research Science Press, pp. 67-72.

[37] Zhou B, Li D, Luo D, Lu R and Yang G (1991). Guide to mitigation of debris flows. Science Press. 